\title{
Matrix Size
}

National Cancer Institute

\section{Source}

National Cancer Institute. Matrix Size. NCI Thesaurus. Code C94929.

This is a quantifying property of a matrix that gives the total number of indexing values in each of its directions. For example matrix size would be specified as $2 \times 3$ if its 6 elements were distributed into 2 rows and 3 columns. 